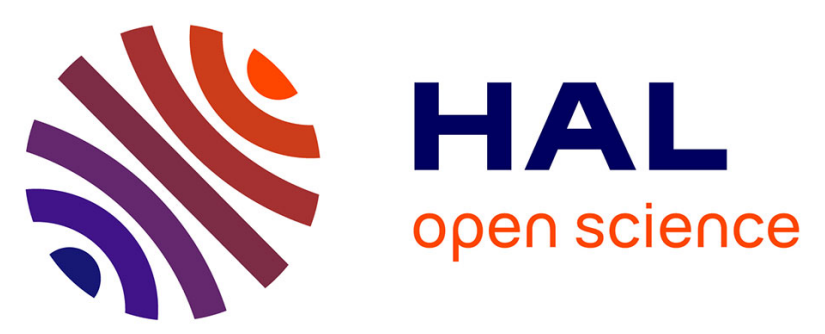

\title{
Flocculation and magnetically-assisted sedimentation of size-sorted beidellite platelets mixed with maghemite nanoparticles
}

\author{
Sofia Housni, Sébastien Abramson, Jean-Michel Guigner, Pierre Levitz,
} Laurent Michot

\section{To cite this version:}

Sofia Housni, Sébastien Abramson, Jean-Michel Guigner, Pierre Levitz, Laurent Michot. Flocculation and magnetically-assisted sedimentation of size-sorted beidellite platelets mixed with maghemite nanoparticles. Nano Research, 2020, 13 (11), pp.3001-3011. 10.1007/s12274-020-2964-9 . hal02952480

\section{HAL Id: hal-02952480 \\ https://hal.sorbonne-universite.fr/hal-02952480}

Submitted on 29 Sep 2020

HAL is a multi-disciplinary open access archive for the deposit and dissemination of scientific research documents, whether they are published or not. The documents may come from teaching and research institutions in France or abroad, or from public or private research centers.
L'archive ouverte pluridisciplinaire HAL, est destinée au dépôt et à la diffusion de documents scientifiques de niveau recherche, publiés ou non, émanant des établissements d'enseignement et de recherche français ou étrangers, des laboratoires publics ou privés. 


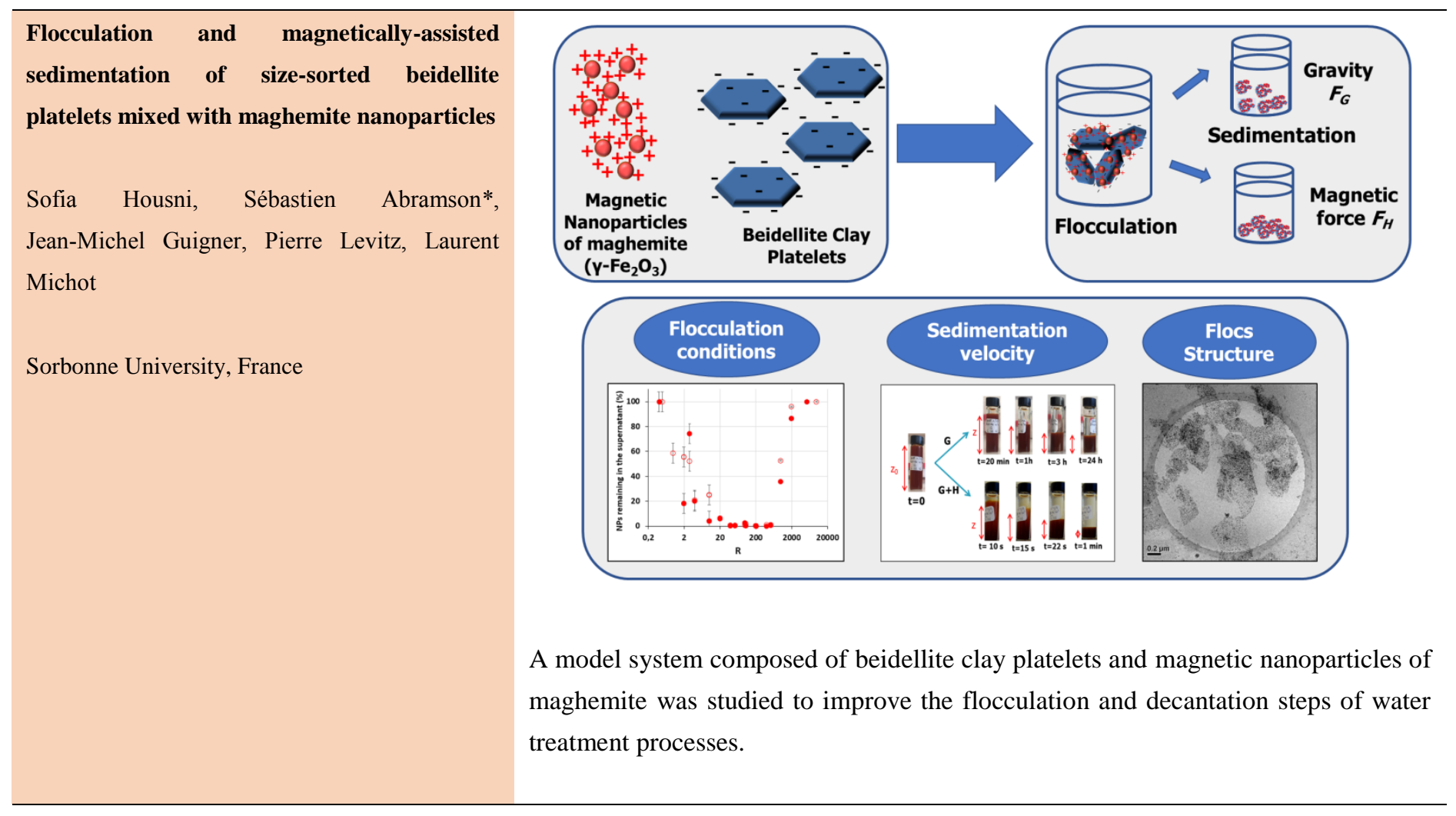





\title{
Flocculation and magnetically-assisted sedimentation of size-sorted beidellite platelets mixed with maghemite nanoparticles
}

\author{
Sofia Housni ${ }^{1}$, Sébastien Abramson ${ }^{1}(\varangle)$, Jean-Michel Guigner ${ }^{2}$, Pierre Levitz ${ }^{1}$, Laurent Michot ${ }^{1}$ \\ 1 : Laboratoire de PHysico-chimie des Electrolytes et Nanosystèmes InterfaciauX (PHENIX UMR 8234, Sorbonne Université - CNRS), Sorbonne \\ Université, Paris, France
}

2 : Institut de Minéralogie, de Physique des Matériaux et de Cosmochimie (IMPMC UMR 7590, Sorbonne Université - IRD - CNRS - MNHN), Sorbonne Université, Paris, France

(C) Tsinghua University Press and Springer-Verlag GmbH Germany, part of Springer Nature 2018

Received: day month year / Revised: day month year / Accepted: day month year (automatically inserted by the publisher)

\begin{abstract}
In this study, the flocculation and the subsequent decantation step of mixed suspensions of $10 \mathrm{~nm}$-sized $\mathrm{y}-\mathrm{Fe}_{2} \mathrm{O}_{3}$ magnetic nanoparticles and $500 \mathrm{~nm}$-sized beidellite clay platelets was investigated. This work may find application in the field of water treatment, specifically the flocculation processes with magnetically assisted sedimentation. After a short description of the preparation and characterization of the raw materials (nanoparticles and clays), the influence of several parameters ( $\mathrm{pH}$, concentrations of nanoparticles and clays...) on the amount of flocculated materials was examined, which gave information on the concentration ranges allowing a complete flocculation, together with a better understanding on the interactions between nanoparticles and clays responsible for flocculation. The optimal conditions for magnetically assisted settling were then determined by comparing for each sample sedimentation velocities under gravity and in the presence of a $\mathrm{Nd}-\mathrm{Fe}-\mathrm{B}$ magnet. Finally, the complex multiscale structure of the flocs in water was explored, through the measurement of several bulk properties (zeta-potential and volume measurements, laser granulometry), while the organization of the materials at a microscopic scale was investigated by cryo-TEM and SAXS.
\end{abstract}

\section{KEYWORDS}

Magnetic separation, nanoparticles, clay, flocculation, decantation, characterization.

\section{Introduction}

Flocculation is a physicochemical process during which colloidal particles in suspensions agglomerate and form bigger particles called flocs. Usually, a flocculating agent, such as an inorganic salt $\left(\mathrm{Al}_{2}\left(\mathrm{SO}_{4}\right)_{3}, \quad \mathrm{FeSO}_{4}, \quad \mathrm{FeCl}_{3} \ldots\right)$ and/or an organic polymer (polydiallyl-dimethylammonium chloride, polyacrylic acid, polyacrylamide...) is added to trigger agglomeration. This method is used in many applications, especially in water treatment [1]. In this field, flocculation is frequently employed in drinking water plants. It aims at eliminating most of the colloidal fraction originally present in raw water under the form of natural organic matter, bacteria, clays or other inorganic particles. In such a process, as floc density is low, floc sedimentation under gravity is rather slow. This major drawback increases the costs and reduces the efficiency of the process. Different techniques have been developed to overcome this issue, including the use of lamellas to increase the settling surface, the addition of high-density particles such as fine sand to "ballast" the flocs, or the clarification methods with sludge contact [2]. However, one of the most promising strategies is based on the replacement of conventional flocculating agents used in water treatment by ferrimagnetic particles made of iron oxide such as magnetite $\left(\mathrm{Fe}_{3} \mathrm{O}_{4}\right)$ or maghemite $\left(\gamma-\mathrm{Fe}_{2} \mathrm{O}_{3}\right)$. The addition of these materials to the aqueous colloidal suspension results in the formation of flocs characterized by a high magnetic susceptibility that can be separated through the use of a magnetic field gradient obtained with a magnet or electromagnet. This technique is particularly relevant since the settling velocity of the ferromagnetic flocs is much faster under the influence of magnetic force, compared to the situation under gravity.

Engineering applications using flocculation with magnetic nanoparticles originated in the early 1940s when magnetite was added to remove organic impurities from wastewater streams [3]. Later, C. De Latour thoroughly studied the effect of the addition of both $\mathrm{Fe}_{3} \mathrm{O}_{4}$ microparticles and $\mathrm{Al}^{3+}$ ions on the removal of suspended solids, bacteria, color, and dissolved phosphorus from waters of various origins [4]. Afterwards, he attempted to highlight some of the general features of magnetically seeded flocculation processes by testing the addition of $\mathrm{Fe}_{3} \mathrm{O}_{4}$ on model colloidal 
suspensions [5]. Still, the most famous industrial water-treatment process using flocculation with magnetic particles is the SIROFLOC process developed by the Australian researchers of CSIRO (Commonwealth Scientific and Industrial Research Organization), during the late 70s [6,7]. In the standard procedure, $\mathrm{Fe}_{3} \mathrm{O}_{4}$ fine particles are directly added to raw water as a flocculating agent. The suspension containing the loaded particles is then sent to a clarifier equipped with a permanent magnet, which results in floc settling and in the removal of color, suspended solids and natural organic matter from the raw water [7]. More recently, the theoretical framework underlying magnetically seeded flocculation has been examined by Yiacoumi et al [8]. In addition, new technologies based on magnetically assisted flocculation have been developed for wastewater or drinking water treatment [9-11].

Although the flocculation by magnetic particles is relatively well developed in the industrial sector, there is a lack of study on the key-parameters that may influence the conditions of flocculation and decantation. In addition, very little work has been published regarding the use of small magnetic nanoparticles (with sizes less than $100 \mathrm{~nm}$ ) as flocculants [12]. Therefore, we propose here to study the flocculation of model colloidal suspensions composed of clay platelets by adding magnetic nanoparticles a few nanometers in size.

Many model systems using iron oxide nanoparticles and clays have been studied [13-29]. Researchers mainly worked using $\mathrm{Fe}_{3} \mathrm{O}_{4}$ or $\gamma-\mathrm{Fe}_{2} \mathrm{O}_{3}$ nanoparticles and a wide range of clay minerals such as montmorillonite, saponite or laponite. The obtained materials have been tested as polymer reinforcing additives [26], drilling fluid components [27], or as pollutant adsorbents [25-28]. However, binary mixtures of clays and iron oxide nanoparticles have never been studied as model systems for magnetically assisted flocculation. Consequently at present, no complete study provides detailed information on the parameters that have to be tuned to obtain optimum flocculation and rapid settling. Another important limit is that the complex and multiscale structure of the heteroaggregates formed during flocculation remains largely unknown, especially when they remain in aqueous phase. Moreover, very little research has been carried out using small angle X-ray or neutron scatterings (SAXS/SANS) techniques, although these methods are particularly suitable for the characterization of complex and disordered clay/nanoparticles binary systems [14, 18, 20, 22].

In the present work, we investigated the flocculation and the subsequent decantation step by adding positively charged 10 nm-sized $\gamma-\mathrm{Fe}_{2} \mathrm{O}_{3}$ nanoparticles having a nearly spherical shape to model colloidal suspensions of beidellite platelets characterized by a mean size of $500 \mathrm{~nm}$. This clay was chosen for its negative charge opposite to that of the $\gamma-\mathrm{Fe}_{2} \mathrm{O}_{3}$ nanoparticles, for its good colloidal stability resulting from exfoliation, and for its low content in iron, which favors a good differentiation between both types of particles by quantitative analysis. Moreover, we employed here size-sorted nanoparticles and platelets, in order to better investigate particle size effects.

Our work was carried out according to the following rationale. First, the raw materials (nanoparticles and clays) were prepared and well-characterized. Hence, we examined the influence of several parameters $(\mathrm{pH}$, concentrations of nanoparticles and clays...) on the amount of flocculated materials. This gave us information on the concentration ranges allowing a complete flocculation, together with a better understanding on the interactions between nanoparticles and clays that are responsible for flocculation. The optimal conditions for magnetically assisted settling were then determined by comparing for each sample sedimentation velocities under gravity and in the presence of a Nd-Fe-B magnet. Finally, the complex multiscale structure of the flocs in water was investigated, thanks to several techniques including zeta-potential and volume measurements, laser granulometry, cryo-TEM, and SAXS. The aim of this paper is to provide a better understanding of the flocculation and sedimentation conditions of the clay platelets and magnetic nanoparticles, and simultaneously to obtain preliminary data on the structure of the resulting flocs. Our objective is to explain how the flocculation and sedimentation characteristics observed for the various experimental conditions are related to flocs structure, with the ultimate goal of clearing the path for designing improved industrial processes.

\section{Experimental part}

\subsection{Synthetic procedures}

\section{a. General procedure for the synthesis of maghemite nanoparticles}

The maghemite $\left(\gamma-\mathrm{Fe}_{2} \mathrm{O}_{3}\right)$ nanoparticles (NPs) were synthetized using a method inspired from the Massart process [30]. The first step is the coprecipitation of $\mathrm{Fe}^{2+}$ and $\mathrm{Fe}^{3+}$ ions in order to get magnetite $\left(\mathrm{Fe}_{3} \mathrm{O}_{4}\right)$ NPs. To complete this first step, a mixture of $585 \mathrm{~mL}$ of iron chloride (III) $\left(\mathrm{FeCl}_{3}\right.$ at $27 \%$, VWR) and 248,5 $\mathrm{g}$ of iron chloride (II) $\left(\mathrm{FeCl}_{2}, \mathrm{VWR}\right)$ was added to $100 \mathrm{~mL}$ of aqueous hydrogen chloride ( $\mathrm{HCl}$ at $37 \%$, VWR). This homogeneous mixture was placed in a separating funnel and dripped in $4 \mathrm{~L}$ of aqueous ammonia (composed of $1 \mathrm{~L} \mathrm{NH}_{3}$ at $20 \%$, VWR and $3 \mathrm{~L}$ of distilled water) under stirring during $4 \mathrm{~h}$.

This suspension was then placed over a magnet, the supernatant was removed, and the NPs were washed with $1 \mathrm{~L}$ of distilled water. Afterward, $360 \mathrm{~mL}$ of aqueous nitric acid $\left(\mathrm{HNO}_{3}\right.$ at $52 \%$, VWR) and $3 \mathrm{~L}$ of distilled water were added, and the suspension was stirred for 30 minutes. Finally, the supernatant was removed using a magnet, and the black mixture obtained at the end of this first step is typical of $\mathrm{Fe}_{3} \mathrm{O}_{4}$ NPs.

The second step is the oxidation of $\mathrm{Fe}_{3} \mathrm{O}_{4}$ by iron nitrate to produce the $\gamma-\mathrm{Fe}_{2} \mathrm{O}_{3}$ NPs. To do so, $323 \mathrm{~g}$ of iron nitrate $\left(\mathrm{Fe}\left(\mathrm{NO}_{3}\right)_{3}\right.$, VWR) was mixed with $800 \mathrm{~mL}$ of distilled water and heated at $90^{\circ} \mathrm{C}$. This new suspension was added to the $\mathrm{Fe}_{3} \mathrm{O}_{4}$ and left stirring at $90^{\circ} \mathrm{C}$ for 30 minutes. A change of color is normally observed during this last step from black to deep brown indicating the formation of the $\gamma-\mathrm{Fe}_{2} \mathrm{O}_{3}$ NPs. After sedimentation and removal of the supernatant, $360 \mathrm{~mL}$ of nitric acid $\left(\mathrm{HNO}_{3}\right.$ at $52 \%$, VWR $)$ and $2 \mathrm{~L}$ of distilled water were added, and the suspension was stirred during $15 \mathrm{~min}$. Finally, the NPs were successively washed three times with acetone, two times with diethyl ether, before being dispersed again by the addition of $1 \mathrm{~L}$ of distilled water.

These NPs were finally sorted by size, adding controlled amounts $(45 \mathrm{~mL})$ of nitric acid $\left(\mathrm{HNO}_{3}\right.$ at $52 \%$, VWR) to $750 \mathrm{~mL}$ of unsorted suspension, which led to a partial flocculation of the NPs. When this suspension was placed over a magnet, the biggest NPs quickly settled allowing us to separate the supernatant containing the smallest NPs. The settled NPs were dispersed again by addition of water. This sorting procedure was repeated twice on these two fractions, which led to six samples of NPs of various sizes. Each of these samples was then washed with acetone and diethylether. 
Finally, an amount of $200 \mathrm{~mL}$ of distilled water was added to the mixtures to obtain stable dispersions of size-sorted magnetic NPs (ferrofluids), with an estimated $\mathrm{pH}$ of 1.8. The dispersions were finally heated at $50^{\circ} \mathrm{C}$ to remove traces of organic solvents. In the present publication, we limit our analysis to a single dispersion of size-sorted magnetic NPs, corresponding to the medium size.

To study the effect of the amount of magnetic NPs on the flocculation of the beidellite platelets, the raw concentrated dispersion was diluted in a given amount of a slightly acidic aqueous solution of $\mathrm{HNO}_{3}$. The effect of the $\mathrm{pH}$ of the dispersions was studied by varying the concentration of $\mathrm{HNO}_{3}$ in these dilution solutions from $10^{-2} \mathrm{~mol} \mathrm{~L}^{-1}$ to $10^{-4} \mathrm{~mol} \mathrm{~L}^{-1}$. We also employed a suspension of aggregated magnetic NPs at $\mathrm{pH} \mathrm{5}$, but in that case the raw dispersion was first flocculated by adding small amounts of $\mathrm{NaOH}$ before being washed several times with distilled water.

\section{b. Purification of beidellite clays}

The clays used in this study originate from a natural deposit (Idaho, USA) and were purchased from the Clay Minerals Society Source Clays Repository. Beidellite is a TOT phyllosilicate with a negative layer charge ranging from -0.2 to -0.6 per unit cell due to isomorphic substitutions of $\mathrm{Si}$ atoms by $\mathrm{Al}$ atoms in the tetrahedral silicate sheets. This moderate charge explains the possible full exfoliation of clay lamellas, in presence of a sufficient amount of water. They were purified according to the following process [31]. First, $200 \mathrm{~g}$ of raw powder was washed three times with $5 \mathrm{~L}$ of aqueous solutions of $1 \mathrm{~mol} \mathrm{~L}^{-1}$ sodium chloride to replace the cations in the interlamellar space by $\mathrm{Na}^{+}$. The clay suspension was then treated using sodium acetate at $\mathrm{pH} 5$ and at $80^{\circ} \mathrm{C}$ to get rid of the carbonates. After that, the suspension was dialyzed against deionized water for at least 15 days in order to eliminate excess ions. The dialyzed suspension was then poured into Imhoff cones and the largest particles constituted of impurities were then discarded. We then obtained a purified clay suspension that was finally sorted by size thanks to successive ultracentrifugation steps at different speeds. This yielded average platelets sizes varying from $200 \mathrm{~nm}$ to $500 \mathrm{~nm}$. This publication is limited to the results concerning the $500 \mathrm{~nm}$ fraction which was obtained after an ultracentrifugation at a speed of $7000 \mathrm{~g}$.

\subsection{Flocculation process}

The flocs were prepared using the following procedure. The same volumes $(4 \mathrm{~mL})$ of NPs and clay suspensions, each of them at an adequate concentration, were mixed and rapidly stirred for 1 minute using a vortex mixer at 10 Hertz (during our first attempts, it had been observed that stirring of the samples for one minute with a vortex mixer at this rate was optimum, in comparison to larger or lower stirring velocities and durations). Then, the sample was left to settle either under the single effect of gravity $(G)$, or under the combined effect of gravity and a magnetic force resulting from a strong magnetic gradient due to a cuboidal $\mathrm{Nd}-\mathrm{Fe}-\mathrm{B}$ magnet located at the bottom of the vessel containing the floc $(\mathrm{G}+\mathrm{H})$. In this case, the magnetic field varied from $0.43 \mathrm{~T}$ at the contact of the magnet to $0.024 \mathrm{~T}$ at the maximum height of the floc suspension (corresponding to a distance of $4.9 \mathrm{~cm}$ from the magnet).

A preliminary study was performed regarding the influence of sedimentation time under $\mathrm{G}$ or $\mathrm{G}+\mathrm{H}$. Under gravity, for low sedimentation times (10 or $20 \mathrm{~min}$ ), although flocculation is almost complete, the flocs are not settled and the percentage of particles (clay and NPs) remaining in the supernatant is high. When a magnet is added, low sedimentation times can lead to a complete removal of the flocs from the supernatant if a high amount of NPs is added, which was not observed for low amounts of NPs. In all cases, complete removal of the flocs from the supernatant is always effective for a sedimentation time of $24 \mathrm{~h}$ over a magnet, and $48 \mathrm{~h}$ under gravity. A higher sedimentation time has no effect on the amount of settled particles, when flocculation is complete. However, in case of uncomplete flocculation of the clay (at very low amount of NPs), very long sedimentation times (more than 5 days) lead to the undesired settling of non-flocculated clay platelets. Therefore, sedimentation times of $24 \mathrm{~h}$ under $\mathrm{G}+\mathrm{H}$ and $48 \mathrm{~h}$ under $\mathrm{G}$ were fixed for the rest of our work.

In order to obtain an extensive analysis of the system, both the concentration in clay platelets, and the initial ratio between the amounts of NPs and clay were varied over a wide range. Three concentrations of clay suspensions $\left([\text { clay }]_{0}=0.15 \mathrm{~g} \mathrm{~L}^{-1}-1.5 \mathrm{~g} \mathrm{~L}^{-1}-\right.$ $7.5 \mathrm{~g} \mathrm{~L}^{-1}$ ) were used, while the dilution of the NPs in the slightly acidic $\mathrm{HNO}_{3}$ solutions was varied from an equivalent iron concentration of $[\mathrm{Fe}]_{0}=7.8 \times 10^{-5} \mathrm{~mol} \mathrm{~L}^{-1}$ to $[\mathrm{Fe}]_{0}=1.56 \times 10^{-1} \mathrm{~mol}$ $\mathrm{L}^{-1}$.

We introduce here the $\mathrm{R}$ parameter that represents the ratio of the number of NPs initially added to the number of clay platelets. This crucial parameter governs the flocculation conditions and can be determined from the clay and NPs concentrations by the equation (1) :

$$
\begin{array}{r}
\mathrm{R}=(\text { Number of nanoparticles }) /(\text { Number of clay platelets }) \\
=\left[\left(\mathrm{M}_{\mathrm{Fe} 2 \mathrm{O} 3} \cdot[\mathrm{Fe}]_{0}\right) /\left(2 \mathrm{~V}_{\mathrm{NP}} \cdot \rho_{\mathrm{Fe} 2 \mathrm{O} 3}\right)\right] \cdot\left[\left(\mathrm{V}_{\text {platelet }} \cdot \rho_{\text {clay }}\right) /\left([\text { clay }]_{0}\right)\right]
\end{array}
$$

Where $[\mathrm{Fe}]_{0}$ is the equivalent iron concentration (in $\mathrm{mol} \mathrm{L}^{-1}$ ), [clay $]_{0}$ the concentration of the clay in the suspension (in $\mathrm{g} \mathrm{L}^{-1}$ ), $\mathrm{M}_{\mathrm{Fe} 2 \mathrm{O} 3}$ ) the molecular weight of maghemite (159.8 $\mathrm{g}$ mol-1), $\rho_{\text {clay }}$ and $\rho_{\mathrm{Fe} 2 \mathrm{O} 3}$ are the densities of the beidellite clay and maghemite (2.62 $\mathrm{g} \mathrm{cm}^{-3}$, and $5.21 \mathrm{~g} \mathrm{~cm}^{-3}$, respectively), $\mathrm{V}_{\text {platelet }}$ and $\mathrm{V}_{\mathrm{NP}}$ the mean volumes of a clay platelet and a maghemite NP, both determined from the mean sizes of the particles measured by TEM microscopy $\left(\mathrm{V}_{\text {platelet }}=[(3 \sqrt{ } 3) / 8] \cdot \mathrm{D}_{\mathrm{F}}^{2} \cdot \mathrm{T}\right.$, where $\mathrm{D}_{\mathrm{F}}=480 \mathrm{~nm}$ and $\mathrm{T}=1$ $\mathrm{nm}$, respectively the mean Feret diameter and the mean thickness of the platelets [31]; $\mathrm{V}_{\mathrm{NP}}=\pi \mathrm{D}^{3} / 6$, where $\mathrm{D}=10.1 \mathrm{~nm}$, the mean diameter of the NPs). This equation has been determined assuming a perfect hexagonal shape for the clay platelets and a perfect spherical shape for the $\gamma-\mathrm{Fe}_{2} \mathrm{O}_{3} \mathrm{NPs}$, and neglecting the effect of particles polydispersity.

\subsection{Characterization methods}

\section{a. XRD}

The X-ray diffraction measurements were conducted using two powder diffractometers (Phillips PW 1130 and Brüker D8). Before analysis, the samples were dried at $70^{\circ} \mathrm{C}$ for $24 \mathrm{~h}$ and then grinded in order to have thin powder. Data were collected from $2 \theta=3^{\circ}$ to $80^{\circ}$ in $0.02^{\circ}$ step at a voltage of $40 \mathrm{kV}$. The diffraction peaks were attributed to $\mathrm{d}_{\mathrm{hkl}}$ spacings using Bragg's equation.

\section{b. TEM and Cryo-TEM}

The dried clay and NPs samples were observed by transmission electron microscopy (TEM) using a JEM JEOL 100 CX microscope operating at $100 \mathrm{kV}$. Furthermore, the frozen floc samples were observed by Cryo-TEM. For this purpose, a $4 \mu \mathrm{L}$ droplet of floc suspension was deposited onto a Quantifoil grid. Excess liquid on the grid was adsorbed with Whatman filter paper. Then, the grid was rapidly plunged into liquid ethane to form a thin 
vitreous ice film. The vitrified sample was then placed into a Gatan 626 liquid-nitrogen cooled cryo-holder and transferred into a LaB6 JEM JEOL 2100 microscope operating at $200 \mathrm{kV}$. Images were recorded on Gatan Ultrascan 1000, 2k x 2k CCD camera, and with a JEOL low dose system (Minimum Dose System, MDS) to protect the thin ice film from any irradiation before imaging and reduce the irradiation during the image capture.

\section{c. DLS and zeta-potential measurements}

DLS and zeta-potential measurements were performed by analysis of the scattered light at $\theta=173^{\circ}(\lambda=633 \mathrm{~nm})$ on a Zetasiser Nano ZS ZEN 3600 apparatus (Malvern Instruments). The variation of the colloidal stability and surface charges of the raw particles (clay and $\gamma-\mathrm{Fe}_{2} \mathrm{O}_{3}$ ) with $\mathrm{pH}$ was measured by titration of the samples using a $\mathrm{pH} 1$ aqueous solution of $\mathrm{HNO}_{3}$ and/or a $\mathrm{pH} 13$ aqueous solution of tetramethylammonium hydroxide (TMAOH). The $\mathrm{pH}$, zeta-potential, and DLS diameter were systematically measured after each addition of the titrating solution. For this experiment, 10 $\mathrm{mL}$ of NPs suspension, with an equivalent iron concentration of $[\mathrm{Fe}]_{0}=7.8 \times 10^{-4} \mathrm{~mol} \mathrm{~L} \mathrm{~L}^{-1}$ and a $\mathrm{pH}$ of 2.1 , was titrated by the TMAOH solution ( $2 \mathrm{~mL}$ added in total). As for the platelets, two separated $10 \mathrm{~mL}$ suspensions, with a clay concentration of $1,5 \mathrm{~g} \mathrm{~L}^{-1}$ and a $\mathrm{pH}$ of 6.6 , were respectively titrated by the $\mathrm{HNO}_{3}$ solution (1 $\mathrm{mL}$ added in total), and the TMAOH solution ( $1 \mathrm{~mL}$ added in total). During these measurements, the ionic strength approximatively ranged from $10^{-2} \mathrm{M}$ to $2.5 \times 10^{-2} \mathrm{M}$ for the NP suspension, and from less than $10^{-4} \mathrm{M}$ to $9.1 \times 10^{-3} \mathrm{M}$ for the clay suspension. In addition, the variation of the zeta-potential of the floc aggregates with the amount of added NPs was measured by a similar procedure. It was checked that these measurements were not affected by the floc sedimentation. The errors on the DLS diameter and zeta-potential were estimated on the basis of the standard-deviation of the measurements and of reproducibility tests.

\section{d. UV-Visible spectrometry}

The concentrations of the NPs and clay platelets remaining in the supernatant after sedimentation of the flocs were determined using a UV-visible UVIKON spectrophotometer. For clay platelets, we directly analyzed the absorbance of the supernatant at $\lambda=650 \mathrm{~nm}$, since it is mainly due to the scattering of the clay platelets (it was first checked that the relationship between clay concentration and absorbance is linear). For NPs, a colorimetric method was used. In the standard procedure, $0.42 \mathrm{~mL}$ of a $37 \% \mathrm{w} / \mathrm{w} \mathrm{HCl}$ aqueous solution was added to $1 \mathrm{~mL}$ of the supernatant. Then, the mixture was heated at $50^{\circ} \mathrm{C}$ for 5 minutes, inducing the dissolution of the NPs into iron ions. Hence, $0.60 \mathrm{~mL}$ of distilled water and $0.48 \mathrm{~mL}$ of a $0.3 \mathrm{~mol} \mathrm{~L}^{-1}$ potassium thiocyanate $(\mathrm{KSCN})$ solution were added. This led to the formation of a red iron complex, which concentration was determined at $\lambda=480 \mathrm{~nm}$ [32]. The errors of measurement were estimated through reproducibility tests and were found larger for the clay concentration, and when the amount of added NPs is low.

\section{e. Settling velocity and final volume of the flocs}

The settling velocity of the aqueous suspensions of the flocs, under $\mathrm{G}$ or $\mathrm{G}+\mathrm{H}$, was determined by measurement of the height of the floc-supernatant interface $(\mathrm{z})$ with time. At $\mathrm{t}=0$, the flocs where homogeneously dispersed in all the liquid phase. The initial height of the floc suspension corresponded to a distance of $\mathrm{z}_{0}=4.9 \mathrm{~cm}$ from the bottom. Two methods of measurement were used. For the samples with slow settling velocity, it was possible to take pictures of the sedimentation front at different times. For the samples with fast settling velocity, it was necessary to film the sedimentation process. We then used the ImageJ software to measure the height of the flocs on every picture. Hence, the evolution of the height was plotted as a function of time. The initial settling velocity was calculated by measuring the slope of the tangent to this kinetics curve, at $\mathrm{t}=0$. The final volume of the flocs was determined by measuring the height of the floc-supernatant interface, after sedimentation for three days under $\mathrm{G}+\mathrm{H}$, and two weeks under $\mathrm{G}$.

\section{f. Laser granulometry}

The mean size of floc particles was determined by laser granulometry using a ACCUSIZER 780/SIS apparatus. Before analysis, it was necessary to dilute the settled flocs with a factor of 5000 by adding $20 \mu \mathrm{L}$ of the suspension to $100 \mathrm{~mL}$ of MilliQ distilled water. Owing to the high dilution used, the concentration of the floc was very weak (between $0.2 \mathrm{mg} \mathrm{L}^{-1}$ and $1 \mathrm{mg} \mathrm{L}^{-1}$, depending of the floc volume), and the ionic strength was nearly zero. This solution was injected into the apparatus and flowed in front of a laser beam, which enabled to determine the individual size of each particle $(500 \mathrm{~nm}$ to $400 \mu \mathrm{m})$ through a combined approach based on light extinction and scattering.

\section{g. SAXS}

The NPs and clay aqueous suspensions, and two NPs/clay settled flocs corresponding to $\mathrm{R}=6$ and $\mathrm{R}=320$ were studied by small angle $\mathrm{X}$-ray scattering (SAXS). The experiments were conducted in European Scientific Radiation Facility (ESRF) in Grenoble on beamlines ID02 and BM26. The samples were put in cells between two thin mica windows with a $0.83 \mathrm{~mm}$ spacer. We realized two sets of measures with the detector either at $1 \mathrm{~m}$ or $30 \mathrm{~m}$, for a beam wavelength of $1.033 \AA$. The obtained values of the scattering vector $q$ ranged from $6.10^{-4}$ to $5.10^{-2} \AA^{-1}$ for the distance of $30 \mathrm{~m}$ and from $6.10^{-3}$ to $0.5 \AA^{-1}$ for the distance of $1 \mathrm{~m}$. The $2 \mathrm{D}$ scattering image was integrated to obtain the raw scattered intensity, $I_{\text {raw }}(q)$. Then, the absolute intensity, $I(q)$ (in $\mathrm{cm}^{-1}$ ) was obtained from $I_{\text {raw }}(q)$ by the following equation :

$I(q)=\left[\left(I_{\text {raw }}(q) / \operatorname{Tr} \cdot t\right)-\left(I_{w a t e r}(q) / \operatorname{Tr}_{\text {water }} \cdot t_{\text {water }}\right)\right] \cdot\left(I_{\text {ref,abs }} / I_{\text {ref,raw }}\right)$

where $\operatorname{Tr}$ and $\mathrm{t}$ are respectively the transmission and thickness of the cell containing the sample, $\mathrm{I}_{\text {water }}(\mathrm{q}), \operatorname{Tr}_{\text {water }}$ and $\mathrm{t}_{\mathrm{water}}$ are respectively the raw scattered intensity, the transmission and thickness of a cell containing water, $I_{\text {(ref,abs) }}$ and $I_{\text {(ref,raw) }}$ are respectively the absolute intensity and the raw intensity of the reference cell containing glassy carbon.

When a SAXS experiment is made with a binary mixture of NPs and clay, the scattered intensity must be written as :

$\mathrm{I}(\mathrm{q})=\Delta \rho_{\text {clay }}{ }^{2} \cdot \mathrm{I}_{\text {clay }}(\mathrm{q})+\Delta \rho_{\mathrm{Fe} 2 \mathrm{O} 3}{ }^{2} \cdot \mathrm{I}_{\mathrm{Fe} 2 \mathrm{O} 3}(\mathrm{q})+\Delta \rho_{\mathrm{Fe} 2 \mathrm{O} 3} \cdot \Delta \rho_{\text {clay }} \cdot \mathrm{I}_{\mathrm{Fe} 2 \mathrm{O} 3 \text {-clay }}(\mathrm{q})$ (3) where $\mathrm{I}_{\text {clay }}(\mathrm{q})$ is the scattering from the clay platelet, $\mathrm{I}_{\mathrm{Fe} 2 \mathrm{O} 3}(\mathrm{q})$ is the scattering from the $\gamma-\mathrm{Fe}_{2} \mathrm{O}_{3} \mathrm{NPs}, \mathrm{I}_{\mathrm{Fe} 2 \mathrm{O} 3 \text {-clay }}(\mathrm{q})$ is the interference term due to the correlations between the clay and $\gamma-\mathrm{Fe}_{2} \mathrm{O}_{3}, \Delta \rho_{\text {clay }}$ is the difference of scattering length density between the clay and water, and $\Delta \rho_{\mathrm{Fe} 2 \mathrm{O} 3}$ is the difference of scattering length density between the $\gamma-\mathrm{Fe}_{2} \mathrm{O}_{3}$ NPs and water.

This equation can be simplified for an aqueous suspension of a single type of isotropic particles. The intensity $\mathrm{I}(\mathrm{q})$ of the scattered beam is then written as :

$$
\mathrm{I}(\mathrm{q})=\mathrm{V}_{\mathrm{p}} \cdot \Phi_{\mathrm{p}} \cdot \Delta \rho^{2} \cdot \mathrm{P}(\mathrm{q}) \cdot \mathrm{S}(\mathrm{q})
$$

where $\mathrm{V}_{\mathrm{p}}$ is the particle volume, $\Phi_{\mathrm{p}}$ is the volume fraction of the 
particles (which can written as $\Phi_{\mathrm{p}}=\mathrm{N} \cdot \mathrm{V}_{\mathrm{p}} / \mathrm{V}$, with $\mathrm{N}$ is the number of particles per volume unit and $\mathrm{V}$ the total volume of the sample), $\Delta \rho^{2}$ is the difference of scattering length density between particles and solvent, $\mathrm{P}(\mathrm{q})$ is the form factor that characterizes the geometry of the particles, and $\mathrm{S}(\mathrm{q})$ is the structure factor that characterizes the interactions between particles.

This equation is well suited to the suspensions of NPs, because of their isotropic shape, but can be also used for the clay suspension, provided that the dilution is sufficiently large to neglect the form factor. It was also employed for the clay/NPs floc at high $\mathrm{R}$ value $(\mathrm{R}=320)$. Indeed, considering the larger scattering length density of $\gamma-\mathrm{Fe}_{2} \mathrm{O}_{3}$ and the larger number of NPs, in such a case, it is valid to neglect the contribution of the clay platelets to the total scattering. Therefore, for this floc, it was possible to determine the structure factor S(q) from the SAXS curve, according to the following procedure. First, the form factor $\mathrm{P}(\mathrm{q})$ was determined using the SAXS curve corresponding to the initial suspension of NPs. For that purpose, this curve was fitted by a theoretical SAXS curve corresponding to polydispersed spherical NPs characterized by a log-normal distribution of their size [33]. The best fit was obtained for a mean diameter of $10.2 \mathrm{~nm}$ and a value of $\sigma$ of $0.35\left(\Phi_{\mathrm{Fe} 203}=\right.$ $0.06 \%)$. This theoretical curve was considered as the form factor $\mathrm{P}(\mathrm{q})$ of the SAXS curve corresponding to the floc at $\mathrm{R}=320$. $\mathrm{S}(\mathrm{q})$ was finally obtained by dividing $\mathrm{I}(\mathrm{q})$ by $\mathrm{P}(\mathrm{q})$.

\section{Results and discussion}

\subsection{Presentation of the raw materials}

\section{a. The $\gamma-\mathrm{Fe}_{2} \mathrm{O}_{3} \mathrm{NPs}$}

The synthetic procedure that was carried out for obtaining the aqueous acidic dispersion of size-sorted $\gamma-\mathrm{Fe}_{2} \mathrm{O}_{3}$ NPs is based on already published works (see the experimental part). The chemical composition of the NPs was confirmed by powder- $\mathrm{X}$ ray diffraction (XRD) and vibrating sample magnetometry. The X-ray diffractogram (see Fig. S1(a) on the Electronic Supporting Information, ESI) of the dry sample displays five main peaks corresponding to distances at 2.96, 2.50, 2.08, 1.60 and $1.46 \AA$, which can be attributed to the $\mathrm{d}_{220}, \mathrm{~d}_{311}, \mathrm{~d}_{400}, \mathrm{~d}_{511}$ and $\mathrm{d}_{440}$ spacings of the $\gamma-\mathrm{Fe}_{2} \mathrm{O}_{3}$ phase. Furthermore, the magnetization-demagnetization curve (see Fig. S1(b)) corresponding to the concentrated aqueous dispersion of the NPs exhibits a high magnetic susceptibility together with no hysteresis, which is typical of the superparamagnetic behavior of few nanometers-sized $\gamma-\mathrm{Fe}_{2} \mathrm{O}_{3}$ NPs [34]. The morphology and size of the NPs have been determined by TEM microscopy. The TEM image (see figure $\mathrm{S} 1(\mathrm{c})$ ) shows that the NPs have a pseudo-spherical shape and are relatively monodisperse. Their mean diameter determined by counting the size of more than 200 NPs on the TEM images is $10.3 \mathrm{~nm}$ (standard deviation $=1.6 \mathrm{~nm}$ ). The resulting size-distribution (see figure $\mathrm{S} 1(\mathrm{~d})$ ) is relatively well modelized by a log-normal curve giving a mean diameter of 10.1 $\mathrm{nm}$ with a $\sigma$ value of 0.14 . The relatively small value of $\sigma$ in comparison to the unsorted initial fraction $(\sigma \approx 0.6)$ confirms the rather good monodispersity of the NPs.

The efficiency of clay flocculation with the NPs is strongly correlated with their respective surface charge and colloidal stability. Since these two parameters strongly depend on $\mathrm{pH}$, their variations were studied by DLS analysis and zeta-potential measurements, respectively. The evolution of the zeta-potential and DLS diameter with $\mathrm{pH}$ for the $\gamma-\mathrm{Fe}_{2} \mathrm{O}_{3}$ NPs is presented in Fig. 1(a). At $\mathrm{pH}<3.5$, the NPs show a DLS diameter of around $25 \mathrm{~nm}$. This value is in accordance with the mean diameter measured by TEM, the small difference resulting from the specificity of the DLS measurement, which gives access to the mean hydrodynamic diameter of the particles. The high colloidal stability of the NPs at acidic $\mathrm{pH}$ is thus confirmed. For $\mathrm{pH}$ values $\leqslant 3.5$, the zeta potential is around $+30 \mathrm{mV}$ revealing that in these conditions, the surface charge of the NPs is positive in agreement with previous studies [35]. When the $\mathrm{pH}$ increases above 3.5, a strong increase of the DLS diameter towards more than $1 \mu \mathrm{m}$ can be observed together with a progressive decrease of the zeta potential that reaches the isoelectric point at $\mathrm{pH}=7-8$, a classical value for $\gamma$ $\mathrm{Fe}_{2} \mathrm{O}_{3}$. Such concomitant evolution of size and zeta potential demonstrates that aggregation of NPs occurs for $\mathrm{pH}>3.5$, as a result of the decreased surface charge of NPs. In basic conditions, or $\mathrm{pH}>8$, the zeta potential of the NPs progressively decreases to negative values, while the DLS strongly and sharply decreases at $\mathrm{pH}>12$. In this $\mathrm{pH}$ range, the NPs are negatively charged, with charge densities high enough to observe a second range of colloidal stability.

\section{b. The clay platelets}

The purification procedure that was carried out for obtaining the aqueous dispersion of size-sorted beidellite clay is based on already published works (see the experimental part). The raw suspension has a low ionic strength $\left(\approx 10^{-4} \mathrm{M}\right)$ and a $\mathrm{pH}$ of 6.5 . Elemental analysis of the dried sample was performed using Energy-dispersive X-ray spectroscopy (EDX) coupled with Scanning Electron Microscopy (SEM). This led us to determine the raw formula of the unit cell which is $\left(\mathrm{Si}_{7,33} \mathrm{Al}_{0,67}\right)\left(\mathrm{Al}_{3,87} \mathrm{Fe}_{0,13}\right) \mathrm{O}_{20}(\mathrm{OH})_{4} \mathrm{Na}_{0,67}$. This raw formula is in accordance with the raw formula provided in a previous work [31]. The cation-exchange capacity (CEC) of the beidellite clay, determined by colorimetry after cation exchange with the cobaltihexamine ion $\left[\mathrm{Co}\left(\mathrm{NH}_{3}\right)_{6}\right]^{3+}$ according to the protocol established by Remy and Orsini [36], is $64 \mathrm{meq} \mathrm{g}^{-1}$ [37]. This value is in accordance with the previously reported values for smectite clays, and confirms the moderate negative charge of the clay platelets

The clay was also characterized by transmission electron microscopy (TEM) and X-ray diffraction (XRD). The TEM image (see Fig. S2(a)) clearly reveals the hexagonal morphology of the clay platelets. The particles are relatively monodisperse, because of the size-sorting procedure, with a mean Feret diameter, determined from ten TEM images on more than 100 particles, of $D_{F}=480 \mathrm{~nm}$, with a standard deviation of $80 \mathrm{~nm}$. The X-ray diffractogram (see Fig. S2(b)) depicts a very intense peak at $2 \theta=7.02^{\circ}$ corresponding to a interplanar distance of $12.5 \AA$. This can be attributed to the $\mathrm{d}_{001}$ basal spacing of the clay layers with one water layer in the interlayer, which is logical for ambient humidity conditions. In addition, several small peaks at $2 \theta=14.8^{\circ}, 21^{\circ} 34.7^{\circ}$ and $61^{\circ}$ (corresponding to distances of $6 \AA, 4.2 \AA, 2.6 \AA$ and $1.45 \AA$ ) can be attributed respectively to the $\mathrm{d}_{002} \mathrm{~d}_{003} \mathrm{~d}_{200}$ and $\mathrm{d}_{060}$ inter-reticular spacings of beidellite, which belongs to the space group $C 2 / m$. The additional peaks at $2 \theta=12^{\circ}, 20^{\circ}$ and $28^{\circ}$ (corresponding to distances of $7.3 \AA, 4.4 \AA$, and $3.2 \AA$ ) are attributed respectively to the $d_{001}$ spacings of kaolinite, and to the $d_{100}$ and $d_{101}$ spacings of quartz (both present as remaining impurities).

The $\mathrm{pH}$ evolution of the zeta-potential and DLS diameter of beidellite platelets can be found in Fig. 1 (b). The DLS diameter 
varies between 250 and $1000 \mathrm{~nm}$ for the studied pHs. Since the value is the same order of magnitude as the size of the platelets measured by TEM, it confirms the good colloidal stability of the clay between $\mathrm{pH} 2$ and 12. Regarding the zeta-potential, it ranges between $-35 \mathrm{mV}$ and $-48 \mathrm{mV}$. Thus, the beidellite platelets display a strong negative charge independent of $\mathrm{pH}$, which can be explained by the fact that surface charge is principally due to structural defaults in the tetrahedral sheet. This high negative surface charge is responsible for the good colloidal stability of the clay platelets.

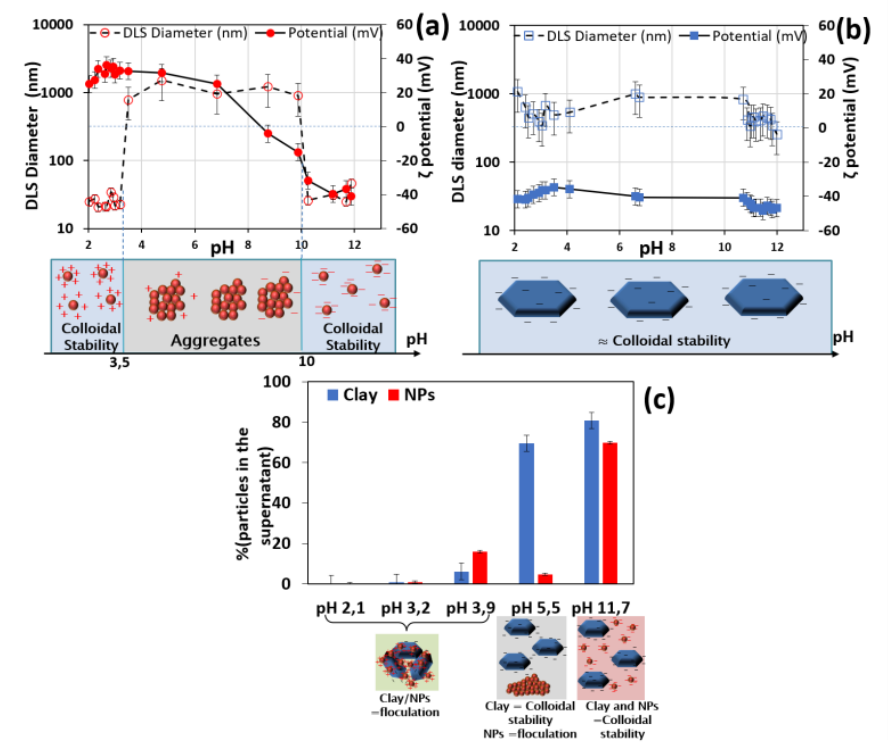

Figure 1 Evolution of the Zeta-potential and DLS diameter with the $\mathrm{pH}$ for the starting materials. (a) maghemite NPs ; (b) beidellite clay. Below: schemes depicting the aggregation state and the surface charges of the materials with respect to $\mathrm{pH}$. (c) Influence of the $\mathrm{pH}$ on the amount of clay and NPs remaining in the supernatant after flocculation and sedimentation $(48 \mathrm{~h}, \mathrm{G})$. Below : Scheme showing the aggregation state of clay/NPs mixtures with respect to $\mathrm{pH}$.

\subsection{Main parameters influencing the amount of flocculated and settled particles}

\section{a. Effect of $\mathrm{pH}$ and ionic strength}

$\mathrm{pH}$ is a key-parameter for the heteroaggregation of both materials due to its strong influence on the surface charge of maghemite. This was confirmed by the UV-visible analysis of the percentages of particles (clays and NPs) remaining in the supernatant after addition of NPs prepared at different $\mathrm{pH}$ to the neutral clay suspension and subsequent decantation (see Fig. 1 (c)). At pH 11.7, most NPs and clays remain in the supernatant. Both particles being negatively charged, repulsive interactions are dominant, and thus

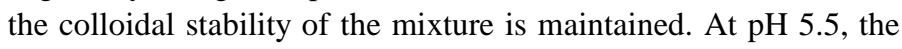
NPs are not charged, and thus homoaggregate. Therefore, the sedimentation of the NPs is almost complete, whereas clay particles mostly remains in the supernatant. At $\mathrm{pH}<4$, both particles are removed from the supernatant indicating that in such conditions, heteroaggregation is dominant. This result illustrates the fact that flocculation requires opposite charges for the two materials. Since the beideillite platelets are negatively charged in the whole $\mathrm{pH}$ range, the NPs had therefore to be dispersed in an acidic $\mathrm{pH}$. It should however be noted that small amounts of clay and NPs remain in the supernatant at $\mathrm{pH} 3.9$, while flocculation and decantation seem to be total at $\mathrm{pH} 2.1$ and 3.2. It is likely that for $\mathrm{pH} 3.9$, which corresponds to the limits of the colloidal stability of the NPs, the surface charge of the NPs is not sufficient to allow an optimal interaction with clay. We finally chose to work at a $\mathrm{pH}$ of 3.2 , because a $\mathrm{pH}$ of 2.1 may lead to the homoaggregation of the clay platelets due to $\mathrm{H}^{+} / \mathrm{Na}^{+}$cation exchanges on their surface [38].

The ionic strength of the samples also constitutes an important parameter that could have an effect on flocculation, especially if the final goal is to design an industrial process.

It has been proven that for monovalent ions, there is no smectite clay flocculation, as long as the ionic strength does not exceed $10^{-2}$ M $[39,40]$. Here, since the ionic strength of the clay suspension is $10^{-4} \mathrm{M}$ and that of the NPs suspensions ranges between $10^{-4} \mathrm{M}$ and $10^{-2} \mathrm{M}$, depending on the $\mathrm{pH}$ of the $\mathrm{HNO}_{3}$ solution used for diluting the NPs, the ionic strength during flocculation ranges between $10^{-4} \mathrm{M}$ and $5.1 \times 10^{-3} \mathrm{M}$. These low values suggests that the amount of ions is insufficient to influence the flocculation process. This was confirmed by a test which has been done by adding a $10^{-3} \mathrm{M} \mathrm{HNO}_{3}$ solution in the clay suspension, in the absence of NPs: after $48 \mathrm{~h}$, no flocculation or sedimentation was observed.

It would also be interesting to explore the high values of ionic strength. Preliminary tests on NPs/clay flocculation were carried out at $\mathrm{pH} 3.2$, with ionic strengths ranging between $3.6 \times 10^{-4} \mathrm{M}$ and $1.5 \mathrm{M}$, through the simultaneous addition of small amounts of $\mathrm{NaCl}$ solutions at the same $\mathrm{pH}$. In all cases, a complete flocculation, followed by a rapid sedimentation (especially under magnetic field) was observed. However, small differences in the sedimentation velocities and flocs volumes were observed. This may indicate that a competition between the NPs and the ions occurs, which would lead to a different structure for the flocs.

\section{b. Influence of the NP/clay ratio}

To study the influence of the initial NP/clay ratio (given as the R parameter) on the amount of flocculated particles, three different clay concentrations were used together with a wide range of NP concentrations. Additional experiments were also carried out at constant $\mathrm{R}$ value with varying clay concentrations in order to assess the effect of clay concentration, independently of the $\mathrm{NP} /$ clay ratio. The percentage of NPs and clay remaining in the supernatant after flocculation and sedimentation under $\mathrm{G}$ or $\mathrm{G}+\mathrm{H}$ was determined by UV-visible analysis, Fig. 2 (a) and (b) display the evolution of these percentages with $\mathrm{R}$. A resulting diagram that describes the different metastable states of clay/NPs mixtures, with respect to the clay and NPs initial concentrations, can be found in Fig. 2 (c).

Three zones can be defined from the shapes of the curves. At low $\mathrm{R}$ values $(R<10)$, significant amounts of NPs and clay platelets are left in the supernatant, and the percentage of non-sedimented particles increases with decreasing $\mathrm{R}$. Two hypotheses can be formulated to explain this result. Either the amount of NPs necessary for the clay flocculation is not enough, and numerous unaggregated particles remain in suspension, or heteroaggregation is complete, but the flocs, because of their too low density, magnetic susceptibility, or size, settle too slowly. In both cases, when $\mathrm{R}$ is less than 10 , flocculation and/or decantation are not complete. For medium values of $R(10<R<320)$, the amount of NPs and clays in the supernatant are less than $5 \%$. This means that both the flocculation and resulting sedimentation of particles is almost complete. For $\mathrm{R}$ values larger than 320 , we can observe that increasing amounts of NPs are left in the supernatant, while the flocculation of clay appears to be complete. Such a tendency can 
be interpreted as follows: in such conditions, adsorbed NPs saturate the clay platelets, and therefore excess NPs that cannot associate with clay particles remain in the supernatant. Obviously such a tendency increases with $\mathrm{R}$ and for very high $\mathrm{R}$ values, almost $100 \%$ of NPs can remain in the supernatant. It must be pointed out that additional tests (not shown) reveal that for a constant $\mathrm{R}$ value, the amount of flocculated particles does not depend on the initial clay concentration.
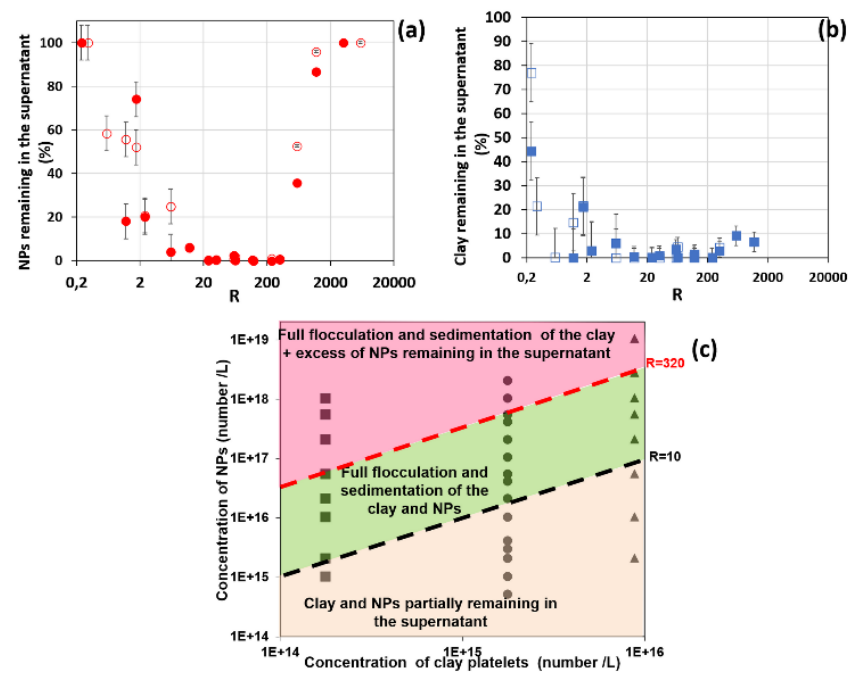

Figure 2 Evolution of the percentage of NPs (a) and clay (b) left in the supernatant after flocculation and settling under gravity (G, 48h, open dots) or over a magnet $(\mathrm{G}+\mathrm{H}, 24 \mathrm{~h}$, filled dots), as a function of $\mathrm{R}$. (c) Resulting diagram of metastable equilibrium of the clay/NP system (after settling under $\mathrm{G}+\mathrm{H}$, 24h).

All these results are summarized in Fig. 2(c), which can be considered as a metastable equilibrium diagram, with respect to the clay and NPs initial concentrations. This diagram clearly exhibits the concentrations limits corresponding to the three above described behaviors. The first area (in red) is observed at high concentration of NPs and low concentration of clay $(\mathrm{R}>320)$. It represents the samples that have entirely flocculated, in spite of an excess of NPs left in the supernatant. The second area (in green), observed at intermediate concentrations of NPs and clay $(10<\mathrm{R}<320)$, matches with the optimum for a total flocculation of both particles. The third area (in orange), obtained at low concentration of NPs and high concentration of clay $(\mathrm{R}<10)$, corresponds to samples for which NPs and clay platelets partially remain in the supernatant after decantation.

\subsection{Settling velocity}

Studying the settling velocity of NPs/clay flocs under gravity or over a magnet is of prime importance. Indeed, water treatment applications not only require complete flocculation, but also a high sedimentation rate. Moreover, the measurement of the settling velocities can provide information on flocs structure. .

To measure this parameter, the freshly prepared flocs were let to settle under $\mathrm{G}$ or $\mathrm{G}+\mathrm{H}$. We observed that for [clay $]_{0}=1.5 \mathrm{~g} \mathrm{~L}^{-1}$, the sedimentation of the materials was always homogeneous (see the photos in Fig. S3), with a clear boundary between the settling materials and the supernatant (i.e. a sharp sedimentation front), and an apparent absence of any concentration gradient for either NPs or clay in the settling flocs (this was further confirmed by analyzing the iron concentration in the flocs at different heights). Therefore, we decided to study floc settling by simply measuring the height of the sedimentation front as a function of time. The kinetics curves for various samples distinguished by their $\mathrm{R}$ values (all prepared with $1.5 \mathrm{~g} \mathrm{~L}^{-1}$ of clay), displaying the evolution with time of the sedimentation front can be found in Fig. S4. The first part of these curves is linear, which means that sedimentation first occurs at a constant rate. Then, the fall gradually stops up to a constant height, which indicates a decrease of the settling velocity down to zero. Many models exist in the literature to describe the settling velocity of isolated or aggregated particles, under gravity [41], or under a magnetic field gradient [42-44]. Here, the obtained curves can be assimilated to Kynch's curves [41], which means that the settling particles constitute a continuous medium that tends to decrease in height. These curves are based on the assumption that the sedimentation rate only depends on the local concentration in particles, which is constant at a given height. The linear domain of the Kinch's curves is explained by the fact that during the first moments of sedimentation, the concentration in particles is constant on the top of the suspension. At the end of the process, the sedimentation rate decreases as the local concentration of particles at the bottom of the suspension increases. The initial settling velocities $\left(\mathrm{v}_{0}\right)$ can be simply calculated from these curves by determining the slope of the linear parts of the curves. Figure 3 displays the evolution of the initial settling velocities as a function of $\mathrm{R}$ for the two sedimentation modes.
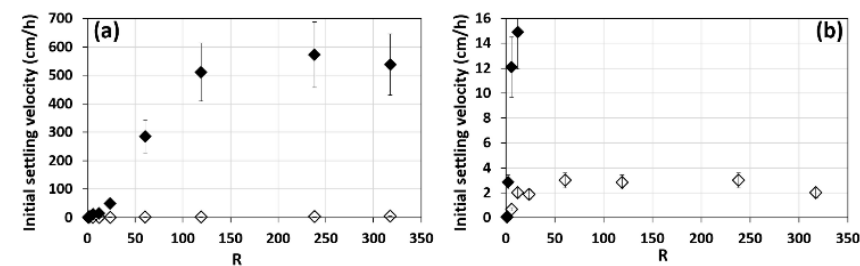

Figure 3 Evolution of the initial settling velocity as a function of $\mathrm{R}$ for the samples settled under $\mathrm{G}$ (open dots) and $\mathrm{G}+\mathrm{H}$ (filled dots) ([clay $]_{0}=1.5 \mathrm{~g} \mathrm{~L}^{-1}$ ) (a) Full Scale ; (b) Enlargement at low values of ordinate.

Several trends can be deduced from the curves of Fig. 3. The first point is that the flocs settle much faster when a magnetic field gradient is added. This result can be explained by the fact that the magnetic force acting on the flocs is much more important than gravity. On the other hand, the sedimentation velocity increases as $\mathrm{R}$ increases, especially under magnetic field, which is probably due to the increase of both gravity and magnetic force with increasing numbers of added NPs in the flocs. Furthermore, the difference between the rates under $\mathrm{G}$ and under $\mathrm{G}+\mathrm{H}$ is increased with increasing $\mathrm{R}$ values. At a value of $\mathrm{R}=12$, the sedimentation velocity under $\mathrm{G}+\mathrm{H}$ is 7.5 times faster than under $\mathrm{G}$, whereas at $\mathrm{R}=240$ the settling velocity under $\mathrm{G}+\mathrm{H}$ is 192 times faster than under $\mathrm{G}$. It should be noted that, from $\mathrm{R}=12$ to $\mathrm{R}=240$, the enhancements in sedimentation velocity are of 1.5 under $\mathrm{G}$, and 38 under $\mathrm{G}+\mathrm{H}$.

To explain the differences in velocities between the two decantation processes, and their increase with $\mathrm{R}$, we calculated the gravitational force, $\mathrm{F}_{\mathrm{G}}$, and the magnetic force, $\mathrm{F}_{\mathrm{H}}$, acting on a single hexagonal clay platelet having several NPs adsorbed on its surface. This entity constitutes a simple structural model of the flocs. The two forces can be obtained by the following equations:

$$
\begin{aligned}
& \mathrm{F}_{\mathrm{G}}=\left(\rho_{\mathrm{F}}-\rho_{\mathrm{w}}\right) \cdot \mathrm{g} \cdot \mathrm{V}_{\mathrm{F}} \\
& \mathrm{F}_{\mathrm{H}}=\mu_{0} \cdot \mathrm{R} \cdot \mathrm{V}_{\mathrm{NP}} \cdot \mathrm{m} \cdot \mathrm{dH} / \mathrm{dz}
\end{aligned}
$$


where $\rho_{\mathrm{F}}$ is the density of the NPs/platelet aggregate, $\rho_{\mathrm{w}}$ the density of the aqueous phase, $g$ the standard gravity, $\mathrm{V}_{\mathrm{F}}$ the volume of the $\mathrm{NPs} /$ platelet aggregate, $\mu_{0}$ the vacuum magnetic permeability, $\mathrm{m}$ the magnetization of the NPs, and $\mathrm{dH} / \mathrm{dz}$ the magnetic field gradient.

The density and volume of the NPs/platelet aggregate can be obtained by the following equations:

$$
\rho_{\mathrm{F}}=\left(\mathrm{V}_{\text {platelet }} \cdot \rho_{\mathrm{F} \text { clay }}=\mathrm{R} \cdot \mathrm{V}_{\text {platelet }}+\mathrm{R} \cdot \mathrm{V}_{\mathrm{NP}} \cdot \rho_{\mathrm{Fe} 2 \mathrm{O} 3}\right) /\left(\mathrm{V}_{\text {platelet }}+\mathrm{R} \cdot \mathrm{V}_{\mathrm{NP}}\right)
$$

The magnetization $\mathrm{m}$ is obtained from the value of the magnetic field $\mathrm{H}$ measured at a given height, $\mathrm{z}$, from the magnet, and using the magnetization curve of the dispersed NPs, giving $\mathrm{m}$ as a function of $\mathrm{H} . \mathrm{dH} / \mathrm{dz}$ is obtained by deriving the experimental curve giving $\mathrm{H}$ as a function of z.The calculation was made for different $\mathrm{R}$ values, and at different sedimentation heights (see Fig. S5). For example, we found that at half the initial height $(\mathrm{z}=2.45$ $\mathrm{cm}), \mathrm{F}_{\mathrm{G}}$ and $\mathrm{F}_{\mathrm{H}}$ are of $2.6 \times 10^{-18} \mathrm{~N}$ and $8.6 \times 10^{-18} \mathrm{~N}$, respectively for $\mathrm{R}=12$, and $7.7 \times 10^{-18} \mathrm{~N}$ and $1.7 \times 10^{-16} \mathrm{~N}$ for $\mathrm{R}=240$ (see Tables $\mathrm{S} 1$ and $\mathrm{S} 2$ for the calculations). Therefore, the ratio $\left(\mathrm{F}_{\mathrm{G}}+\mathrm{F}_{\mathrm{H}}\right) / \mathrm{F}_{\mathrm{G}}$ is 4.2 for $\mathrm{R}=12$, and 23.2 for $\mathrm{R}=240$. When $\mathrm{R}$ increases from 12 to 240 , $F_{G}$ and $F_{G}+F_{H}$ are enhanced by factors of 2.9 and 16 , respectively. Although there is no simple relations between the ratios obtained from the experimental velocities and those obtained from the theoretical forces, it is interesting to note that there is a clear correlation between both values. Therefore, our results may well be explained in terms of an increase of the gravity and magnetic force and of their difference, as the value of $\mathrm{R}$ increases, due to the higher density and higher magnetic susceptibility of the flocs. However, the effect of the magnetic field on sedimentation seems to be minimized when the calculated values of $\mathrm{F}_{\mathrm{G}}$ and $\mathrm{F}_{\mathrm{H}}$ are used. To explain this difference, it is important to mention that the strength of $\mathrm{F}_{\mathrm{H}}$ increases with the proximity from the magnet, and thus the $\left(\mathrm{F}_{\mathrm{G}}+\mathrm{F}_{\mathrm{H}}\right) / \mathrm{F}_{\mathrm{G}}$ ratio increases as the height decreases. Considering that the floc particles are interconnected, the effect of the magnetic field at low height may have strong importance on the global sedimentation velocity. Furthermore, the real structure of the floc particles is probably much more complex that the simple model used for the calculations, which can strongly impact sedimentation velocities. We attempted to elucidate this complex structure through different approaches, which are reported in the next part of our work

\subsection{Flocs characterization}

To obtain a first description of the flocs structure, several bulk properties including surface charge, total volume after sedimentation and granulometric size were measured, while the organization of the materials at a microscopic scale was partially determined by cryo-TEM and SAXS.

a. Surface charge of the flocs by measurement of the zeta-potential We determined the zeta-potential of the flocs after $48 \mathrm{~h}$ of sedimentation under $\mathrm{G}$, for different values of $\mathrm{R}$ and at [clay $]_{0}=1.5$ $\mathrm{g} \mathrm{L}^{-1}$. The results are displayed in Fig. 4 (a).
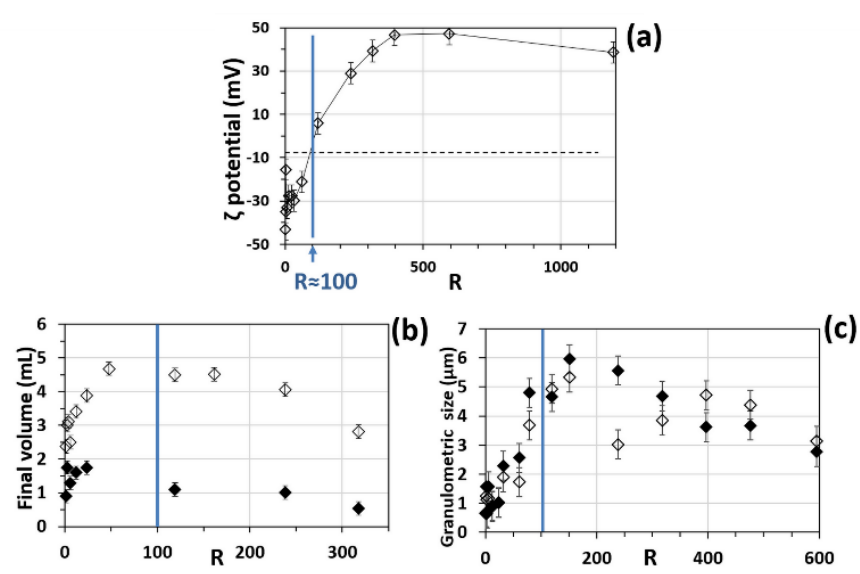

Figure 4 Evolution of several bulk properties of the flocs as a function of the $\mathrm{R}$ parameter and the sedimentation modes (open dots $=\mathrm{G}, 48 \mathrm{~h}$; filled dots = $\mathrm{G}+\mathrm{H}, 24 \mathrm{~h}$ ). The value of [clay $]_{0}$ is always $1.5 \mathrm{~g} \mathrm{~L}^{-1}$. (a) Zeta-potential (b) Total volume of the flocs and (c) Granulometric size (the vertical line at $R=100$, corresponds to the isoelectric point of the flocs).

Figure 4(a) clearly shows the increase of the zeta-potential with R. For low $\mathrm{R}$ values, the flocs have a negative zeta-potential with a value close to that of clay platelets. This means that the amount of NPs is not enough to neutralize all the negative charges of the clay platelets. As the amount of NPs increases, those negative charges are progressively neutralized until reaching the isoelectric point, when the zeta potential equal zero, for a value of $R$ of approximatively 100 . At this stage, either all negative charges are neutralized, or the flocs behave like a zwitterion, which means that they contain the same amount of positive and negative charges. Above $R=100$, the flocs have a positive zeta-potential, which indicates that adsorption on the clay platelets continues, although there is an excess of NPs with respect to their amount necessary to neutralize the negative charges of the clay platelets. At very high $R$ values $(R>320)$, the positive surface charge of the flocs does not evolve, which is related to the saturation of the clay surface by adsorbed NPs. Thus, zeta-potential measurements highlight the existence of two types of flocs distinguished by the sign of their surface charge, depending on the amount of added NPs.

\section{$b$. Total volumes of the flocs after sedimentation}

Settling velocity measurements also provide estimate of floc total volumes after sedimentation. Such a value is somehow linked to the internal floc structure, and is also important for water treatment applications, since small volumes after sedimentation allow an easier flocs recycling $[1,41]$. Flocs volumes were determined after sedimentation for three days under $\mathrm{G}+\mathrm{H}$, and two weeks under $\mathrm{G}$ (no major evolution was observed for longer periods of sedimentation). It is important to note that a preliminary study using thermogravimetric analysis revealed that the flocs are composed of more than $99 \%$ of water after sedimentation. This indicates that most of the volume of the flocs is due to water, and that the intrinsic contribution of clay platelets and NPs is extremely weak.

Figure $4 \mathrm{~b}$ shows the evolution of the volumes as a function of R, for the two decantation modes ([clay $\left.]_{0}=1.5 \mathrm{~g} \mathrm{~L}-1\right)$. The settling type has a strong influence on the final volumes. The volumes range between $30 \%$ and $58 \%$ of the initial volume $(\mathrm{V}=8 \mathrm{~mL})$ after sedimentation under $\mathrm{G}$, while they remain between $6 \%$ and $22 \%$ after sedimentation under $\mathrm{G}+\mathrm{H}$. Thus, the presence of a 
magnet lead to lower flocs volumes, whatever the value of $\mathrm{R}$. This first result can be explained by the fact that the magnetic force is much more important than gravity (especially at the end of the sedimentation process, when the distance to the magnet is short), which implies a stronger compression of the flocs. It should also be noted that the difference in volume between the two settling modes increases as $\mathrm{R}$ increases, which is correlated to the increases of the $\left(\mathrm{F}_{\mathrm{G}}+\mathrm{F}_{\mathrm{H}}\right) / \mathrm{F}_{\mathrm{G}}$ ratio with $\mathrm{R}$.

The second factor influencing flocs volumes is the amount of added NPs. The two curves of Fig. 4(b) have a similar shape, with an increase of volumes up to a maximum, before a progressive decrease. The position of the maximum on the $\mathrm{R}$ axis seems to depend on the decantation mode. Interestingly, under gravity alone the maximum is found at $\mathrm{R}=100$, which corresponds to the isoelectric point of the flocs. When a magnet is added, the maximum is found at a slightly lower value $(R=25)$, and the drop in volume after the maximum is particularly strong (70\% of loss).

To explain these observations, we propose that at low value of $\mathrm{R}$, the addition of the NPs to the clay disturbs platelets stacking, creating disordered aggregates, which tends to increase the volume of the sediment. This trend is reinforced when the amount of NPs is increased, up to a certain limit, which corresponds, under G, to the isoelectric point of the flocs. At high $\mathrm{R}$ value, the increased strengths of the gravity and magnetic force that lead to enhanced floc compression, seem to be dominant. Such an effect is particularly intense under a magnetic field, explaining that the maximum is found for a lower value of $\mathrm{R}$ and that a stronger decrease of the floc volume occurs beyond this maximum.

\section{c. Mean size of the floc particles by laser granulometry}

The samples were characterized by laser granulometry after sedimentation and dilution in a high amount of water. Figure 4 (c) regroups the evolution with $\mathrm{R}$ of the mean size of the particles obtained by this technique, for flocs settled under $\mathrm{G}$ and under the $\mathrm{G}+\mathrm{H}\left([\text { clay }]_{0}=1.5 \mathrm{~g} \mathrm{~L}^{-1}\right)$.

Flocs made from clay and a flocculating agent (inorganic ions, polymers or NPs) are complex arrangements of solid particles and water. They have an irregular shape with different basic units corresponding to different scales. Some authors proposed an organization with three size scales [1,45]. According to their interpretation, primary particles are strongly aggregated into clusters of few micrometers, which are grouped at larger scales into aggregates of several tens of micrometers, themselves weakly associated into superaggregates at the millimeter scale. The question of which size is measured by laser granulometry is then important. Since a high dilution of the samples is necessary to use laser granulometry, the weak cohesion of aggregates and superaggregates is probably broken. In addition, the scale of the measured sizes is less than ten micrometers. Therefore, it is highly probable that laser granulometry gives access to the size of the primary clusters of NPs and clay.

Figure 4(c) reveals that laser measured size is poorly affected by the mode of decantation. Taking into account its strong effect on the total volumes, the decantation mode effectively influences the structure of the materials, but at a larger scale than that measured by laser granulometry. To the contrary, the mean size is strongly impacted by the amount of added NPs. When R is lower than 150 , we observe an increase of the flocs sizes from $500 \mathrm{~nm}$, to $6 \mu \mathrm{m}$. When $\mathrm{R}$ is larger than 150 , the flocs size decreases down to $3 \mu \mathrm{m}$. These results can be interpreted in relation to zeta-potential measurements. At very low $\mathrm{R}$ values, the flocs bear a strong negative charge, and the measured sizes (around $500 \mathrm{~nm}$ ) are not far from the initial size of the clay platelets. Thus, the presence of high electrostatic repulsions implies a weak cohesion between the primary particles, which is probably broken by the high dilution used for the analysis. For larger R values, as the amount of added NPs increases, the negatives charges of the platelets are progressively neutralized which means that the electrostatic repulsions decrease. This leads to stronger aggregation between the platelets, and therefore to increased sizes for the Clay/NPs clusters. The highest sizes are reached close to the isoelectric point, where the electrostatic repulsions are minimal. Above $\mathrm{R}=150$, the addition of the NPs leads to positively charged flocs, again exhibiting electrostatic repulsions. The decrease of the granulometric size means the decrease of the clusters size, which is explained by the decrease of the cohesion between the particles. On the other hand, a correlation between the total volumes and the particles sizes is also observed, a high size for primary aggregates implying a large total volume. However, since the two parameters are not affected in the same manner by the decantation mode, the flocs volume also depends on aggregation at larger scale. Furthermore, it can be noted that the maxima of the total volume and granulometric size are not found exactly at the same values of R.

\section{d. Cryo-transmission electronic microscopy (Cryo-TEM)}

Several floc samples were analyzed by Cryo-TEM, because this method avoids the undesired aggregation of the particles during drying. Figure 5 exhibits Cryo-TEM images of the flocs after sedimentation $(\mathrm{G}, 48 \mathrm{~h})$ for $\mathrm{R}=320$ and 6 ([Clay $\left.]_{0}=1.5 \mathrm{~g} \mathrm{~L}^{-1}\right)$.

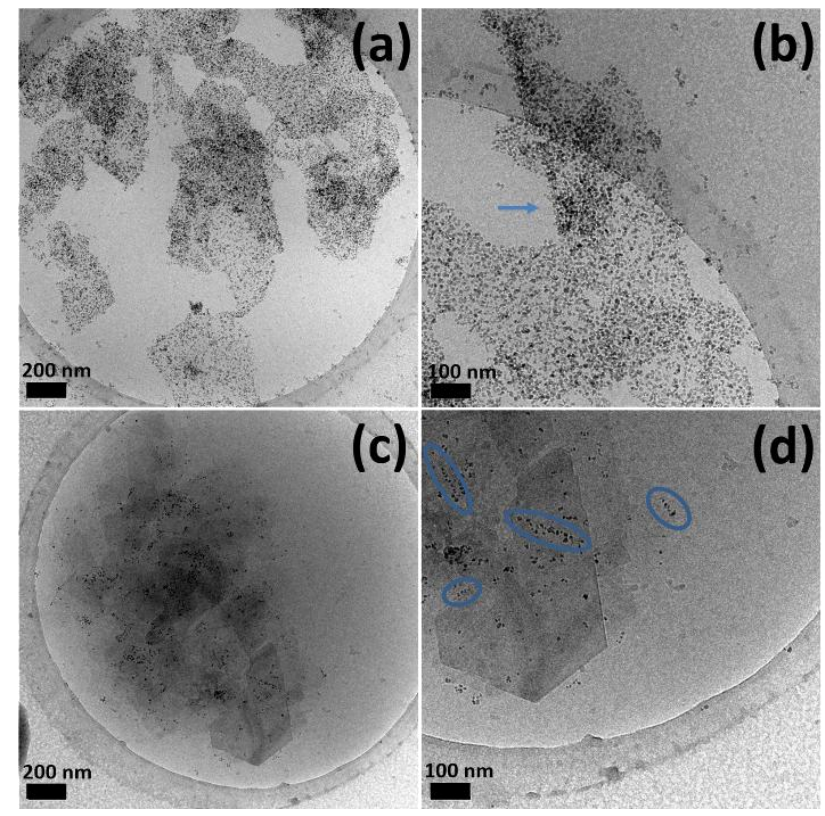

Figure 5 Cryo-TEM images of the flocs ([clay $]_{0}=1.5 \mathrm{~g} \mathrm{~L}^{-1}$; sedimentation $\mathrm{G}$, 48h). (a) and (b) $\mathrm{R}=320$ : (a) low magnification, (b) high magnification (the arrow marks the position of a laterally oriented platelet). (c) and (d) $R=6$ : (c) low magnification, (d) high magnification (the rings mark some NPs located on the platelet edges).

As seen in Fig. 5(a) and 5(b), for large values of $R(R=320)$, the NPs are regularly deposited on the faces of the clay platelets. The mean distance between two adjacent NPs centers obtained by a short analysis of the cryo-TEM images is $108 \AA$, which confirms 
that the adsorbed NPs are in close contact. In addition, it seems that the coated platelets are irregularly stacked through face-to-face aggregation (darker zones of the pictures). We can also observe platelets that are not in the same orientation (they look like needles on the pictures : see the arrow on Fig. 5(b)), which may indicate the presence of face-to-edge or edge-to-edge aggregation. The extent of the aggregate is more than $2.5 \mu \mathrm{m}$, which is in agreement with the mean sizes obtained by laser granulometry. For a low NPs amount ( $\mathrm{R}=6$, Fig. 5(c) and 5(d)), the NPs seems to be preferentially localized on platelets edges (see the rings on Fig. $5(d)$ ). Face-to-face aggregation of the clay is only observed. In comparison to the case with high amounts of NPs, the aggregates appear more compact, but have a lower size. Using Cryo-MET, we thus obtained qualitative information on the location of the NPs and the morphology of the primary aggregates. However, this technique is limited here to a two-dimensional view of few clusters. Therefore, it is important to complete these results by Small Angle $\mathrm{X}$-ray Scattering that provides averaged information on floc structure.

\section{e. Small Angle X-ray Scattering}

Two floc samples corresponding to a low and high amount of NPs, respectively $(R=6$ and $R=320$ ), were characterized by SAXS. For comparison purposes, the NPs dispersion and the clay suspension were also analyzed. Figure 6 presents the evolution of the obtained SAXS curves giving the scattered intensity $\mathrm{I}(\mathrm{q})$ plotted as a function of the scattering vector $\mathrm{q}$.
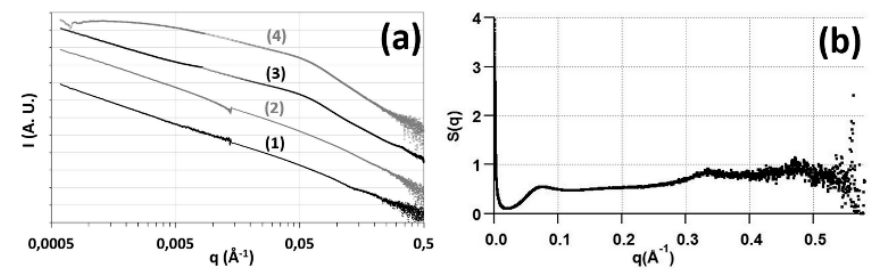

Figure 6 (a) SAXS curves of the aqueous suspensions for the initial materials and two flocs samples: (1) Clay suspension $1.5 \mathrm{~g} \mathrm{~L}^{-1}$, (2) clay/NPs floc, $\mathrm{R}=6$ ([Clay $]_{0}=1.5 \mathrm{~g} \mathrm{~L}^{-1}$ ), (3) clay/NPs floc, $\mathrm{R}=320$ ([Clay $]_{0}=1.5 \mathrm{~g} \mathrm{~L}^{-1}$ ), (4) NPs dispersion $\left([\mathrm{Fe}]_{0}=4.2 \times 10^{-2} \mathrm{~mol} \mathrm{~L}^{-1}, \mathrm{HNO}_{3}, \mathrm{pH}=3\right)$. (b) Structure factor obtained from the SAXS curve (3) corresponding to the clay/NPs floc at $\mathrm{R}=320$.

For the clay platelets alone (curve (1)), the SAXS data are well fitted by a single power law with an exponent of -2.3 which can be attributed to the form factor of the clay platelets [31, 33]. Concerning the $\gamma-\mathrm{Fe}_{2} \mathrm{O}_{3}$ NPs (curve (4)), the curve can be divided into several parts. At high q (q $\geq 7.10-2 \AA^{-1}$ ), the data are fitted via a power law with exponent -4 , due to the form factor of the spherical NPs, in agreement with Porod's law [20, 33]. At intermediate $\mathrm{q}$ values $\left(5.10-3 \AA^{-1} \leq \mathrm{q} \leq 7.10^{-2} \AA^{-1}\right)$, the curve is proportional to $\mathrm{q}^{-1.8}$, while at very low $\mathrm{q}$ values $\left(6.10^{-4} \AA^{-1} \leq \mathrm{q} \leq\right.$ $5.10^{-3} \AA^{-1}$ ) a plateau is observed. Such a behavior is characteristic of some slightly aggregated polydispersed NPs. The exponent of -1.8 is correlated to the structure factor of the NPs aggregates, while the plateau can be modeled by Guinier' s law, which gives access to $\mathrm{Rg}$, the mean radius of gyration of the aggregates [33]. The calculation gave us a value of $\operatorname{Rg} \approx 40 \mathrm{~nm}$.

The SAXS curves corresponding to NPs/clays aqueous flocs (curves (2) and (3)) present two distinct regions. The first part of the curves at high $q$ values $\left(q \geq 7.10^{-2} \AA^{-1}\right.$ ), is well fitted by a power law with an exponent between -3 and -4 , while the second part of the curve ( $\mathrm{q} \leq 7.10^{-2} \AA^{-1}$ ) can be fitted by a power law with an exponent close to -2 . The exact values of these exponents depend on the amount of added NPs. At high q, the exponent is -3.2 for $\mathrm{R}=6$, a value intermediate between those obtained for the pure NPs and clay. This may result from the combined contribution of the form factors of both types of particles. For $\mathrm{R}=320$, this exponent decreases to -3.8 , a value close to that of the pure NPs. This suggests that for this sample, the main contribution to the form factor is due to maghemite, which may be caused by the larger number of NPs and by their larger scattering length density, in comparison to the clay platelets. At low q, the exponent is -2.3 for $\mathrm{R}=6$, a value identical to that of the clay suspension. This may be explained by a similar structure for the clay suspension, and for the flocs containing a low amount of NPs, at least for the small scales studied by SAXS. This similarity may result from the keeping of relatively high repulsions between the clay platelets for these flocs. Interestingly, the value of the exponent at low $\mathrm{q}$ increases to -1.8 for $\mathrm{R}=320$. The shape of the curve at low $\mathrm{q}$ for the floc at $R=320$ is not similar to that of the single NPs, since no plateau is observed at very low q value. Thus, this specific shape may reflect the existence of a structure factor characteristic of the flocs containing a high amount of NPs.

To confirm this hypothesis, we attempted to extract the structure factor $\mathrm{S}(\mathrm{q})$ from the SAXS curve corresponding to the floc at $\mathrm{R}=320$, using a procedure that neglects the contribution of the clay to the total scattering (see the experimental part). The structure factor is shown in Fig. 6 (b). First, it should be noted that $S(q)$ does not tend to 1 at high $\mathrm{q}$ values, indicating that the clay scattering cannot be totally ignored. Two wide peaks can be observed, the first one corresponding to a distance of $19 \AA$, and the second one, at lower q value, corresponding to $90 \AA$. The smaller distance may be assigned to a stacking of clay platelets separated by three water layers in the interlamellar space, while the higher could be attributed to the mean distance between two neighboring NPs centers, in good accordance with the value obtained from the cryo-TEM images. Furthermore, at low $q$ values, the strong increases of $\mathrm{S}(\mathrm{q})$ with decreasing $\mathrm{q}$ proves the predominance of attractions between particles and confirms the high degree of aggregation in this sample. At this stage, it is however difficult to explain the power law in $\mathrm{q}^{-1.8}$. It is possible that the value of 1.8 corresponds to the fractal dimension of the aggregates. The characterization of this floc by other scattering and imaging methods, which are more suitable for higher scales is therefore necessary. In addition, the negligible contribution of the clay to the global scattering has to be confirmed by SANS measurements.

\section{Conclusion}

We studied the aggregation and sedimentation of flocs composed of positively charged $\gamma-\mathrm{Fe}_{2} \mathrm{O}_{3}$ NPs having a mean diameter of 10 $\mathrm{nm}$ and negatively charged beidellite platelets with a mean size of $500 \mathrm{~nm}$. This model system allows a better understanding of the magnetically assisted flocculation processes, which has been used for a long time in water-treatment. First, the influence of the experimental conditions on the conditions of flocculation and settling was determined. Thus, we highlighted the importance of $\mathrm{pH}$ for obtaining optimal flocculation and decantation. Furthermore, we looked into the influence NPs/clay ratio, named as the $\mathrm{R}$ parameter. We proved that the clay and NPs can entirely flocculate and settle when R ranges between 10 and 320. Hence, we studied 
the influence of the $\mathrm{R}$ parameter and the decantation mode on settling velocities. We demonstrated that the rates can be considerably improved using a magnet and increasing the value of $\mathrm{R}$. These trends are correlated to the increase of the difference between the strengths of gravity and magnetic force as $\mathrm{R}$ increases. Therefore, our results suggest that $10 \mathrm{~nm}$-sized magnetic NPs can be used as flocculating agent, but they have to be added in relatively high amount to obtain a total flocculation followed by a rapid decantation over a magnet.

In addition, we successfully measured the zeta-potential of the flocs, their total volume and their granulometric size. We observed that these three parameters are related. For R values between 2 and 130, the added NPs progressively neutralize the negative surface charges of the clay platelets. We can then observe the formation of primary aggregates with a size and cohesion increasing with $\mathrm{R}$, which implies larger total volumes for the flocs after sedimentation. When $\mathrm{R}$ is equal to 100 , the isoelectric point of the flocs is reached. At larger $\mathrm{R}$ values, the size and cohesion of the positively charged floc particles tend to decrease, and the compression effects due to the gradient magnetic field and the gravity causes a decrease of the total volumes. At a smaller scale, Cryo-TEM images showed that the NPs are homogeneously dispersed on the faces of the clay platelets which exhibit several modes of aggregation. Finally, the SAXS analysis gave us a first idea of the organization of the aggregates at the nanometer level. At low $\mathrm{R}$ value, the structure of the flocs is close to that of the initial clay suspension, for which repulsive interactions are dominant. At larger $\mathrm{R}$ value, the particles are strongly aggregated which implies a structure factor characterized by an exponent of -1.8. However, to have a better understanding of the observed properties, a multi-scale characterization of the flocs needs to be performed, through the use of additional imaging and scattering techniques.

\section{Acknowledgements}

We wish to kindly thank Delphine Talbot and Aude Michel for their technical support, and Cedric Boissiere for the fruitful discussions. We equally acknowledge the local staffs of the ID02 and BM26 lines of the European Scientific Radiation Facility (ESRF) in Grenoble.

Electronic Supplementary Material: Supplementary material about raw material characterization, the settling velocity, calculation of the forces $\mathrm{F}_{\mathrm{G}}$ and $\mathrm{F}_{\mathrm{H}}$ as well as their comparison is available in the online version of this article at http://dx.doi.org/10.1007/s12274-*********** (automatically inserted by the publisher).

\section{References}

[1] Bottero, J.-Y.; Lartiges, B. Séparation liquide/solide par coagulation-floculation: les coagulants-floculants, mécanismes d'agrégation, structure et densité des flocs. / Liquid/solid separation by coagulation-flocculation, coagulants-flocculants, flocs structure and density. Sciences Géologiques. Bulletin 1993, 46 (1), 163-174. https://doi.org/10.3406/sgeol.1993.1902.

[2] Suez. Processus élémentaires du génie physico-chimique en traitement de l'eau https://www.suezwaterhandbook.fr/eau-et-generalites/processus-elem entaires-du-genie-physico-chimique-en-traitement-de-l-eau (accessed Jul 30, 2018)

[3] Urbain, O. M.; Stemen, W. R. Process for Treating Liquids. US2232294A, February 18, 1941.

[4) Latour, C. D. Magnetic Separation in Water Pollution Control. IEEE

Transactions on Magnetics 1973, 9 (3], 314-316. https://doi.org/10.1109/TMAG.1973.1067685.

[5] Latour, C. de; Kolm, H. Magnetic Separation in Water Pollution Control - II. IEEE Transactions on Magnetics 1975, 11 (5), 1570-1572. https://doi.org/10.1109/TMAG.1975.1058801.

[6] Bolto, B. A.; Spurling, T. H. Water Purification With Magnetic Particles. In Fourth Symposium on our Environment; Springer, Dordrecht, $1991 ; \quad$ pp 139-143. https://doi.org/10.1007/978-94-011-2664-9_14.

[7] SIROFLOC - unique method of water treatment https://csiropedia.csiro.au/sirofloc/ (accessed Jul 26, 2018).

[8] Yiacoumi, S.; Rountree, D. A.; Tsouris, C. Mechanism of Particle Flocculation by Magnetic Seeding. Journal of colloid and interface science 1996, 184 (2), 477-488.

[9] Karapinar, N.; Hoffmann, E.; Hahn, H. H. Magnetite Seeded Precipitation of Phosphate. Water research 2004, 38 (13), 3059-3066.

[10] Cort, S. L. Magnetic Separation and Seeding to Improve Ballasted Clarification of Water. US7820053B2, October 26, 2010.

[11] Cort, S. L. Magnetic Ballast Clarification Designs and Applications. US20160221845A1, August 4, 2016.

[12] Lohwacharin, J.; Oguma, K.; Takizawa, S. Use of Carbon Black Nanoparticles to Mitigate Membrane Fouling in Ultrafiltration of River Water. Separation and Purification Technology 2010, 72 (1), $61-69$.

[13] Tombácz, E.; Csanaky, C.; Illés, E. Polydisperse Fractal Aggregate Formation in Clay Mineral and Iron Oxide Suspensions, PH and Ionic Strength Dependence. Colloid and Polymer Science 2001, 279 (5), 484-492.

[14] Cousin, F.; Cabuil, V.; Levitz, P. Magnetic Colloidal Particles as Probes for the Determination of the Structure of Laponite Suspensions. Langmuir 2002, 18 (5), 1466-1473.

[15] Ji, Y.-Q.; Black, L.; Weidler, P. G.; Janek, M. Preparation of Nanostructured Materials by Heterocoagulation Interaction of Montmorillonite with Synthetic Hematite Particles. Langmuir 2004, 20 (22), 9796-9806.

[16] Tombacz, E.; Libor, Z.; Illes, E.; Majzik, A.; Klumpp, E. The Role of Reactive Surface Sites and Complexation by Humic Acids in the Interaction of Clay Mineral and Iron Oxide Particles. Organic Geochemistry 2004, 35 (3), 257-267.

[17] Galindo-Gonzalez, C.; De Vicente, J.; Ramos-Tejada, M. M.; Lopez-Lopez, M. T.; Gonzalez-Caballero, F.; Duran, J. D. G. 
Preparation and Sedimentation Behavior in Magnetic Fields of Magnetite-Covered Clay Particles. Langmuir 2005, 21 (10), $4410-4419$

[18] Szabó, T.; Bakandritsos, A.; Tzitzios, V.; Papp, S.; Korösi, L.; Galbács, G.; Musabekov, K.; Bolatova, D.; Petridis, D.; Dékány, I. Magnetic Iron Oxide/Clay Composites: Effect of the Layer Silicate Support on the Microstructure and Phase Formation of Magnetic Nanoparticles. Nanotechnology 2007, 18 (28), 285602.

[19] Esteban-Cubillo, A.; Marco, J. F.; Moya, J. S.; Pecharromán, C. On the Nature and Location of Nanoparticulate Iron Phases and Their Precursors Synthetized within a Sepiolite Matrix. The Journal of Physical Chemistry C 2008, 112 (8), 2864-2871.

[20] Cousin, F.; Cabuil, V.; Grillo, I.; Levitz, P. Competition between Entropy and Electrostatic Interactions in a Binary Colloidal Mixture of Spheres and Platelets. Langmuir 2008, 24 (20), 11422-11430.

[21] Orolínová, Z.; Mockovčiaková, A. Structural Study of Bentonite/Iron Oxide Composites. Materials Chemistry and Physics 2009, 114 (2-3), 956-961.

[22] Paula, F. L. de O.; da Silva, G. J.; Aquino, R.; Depeyrot, J.; Fossum, J. O.; Knudsen, K. D.; Helgesen, G.; Tourinho, F. A. Gravitational and Magnetic Separation in Self-Assembled Clay-Ferrofluid Nanocomposites. Brazilian Journal of Physics 2009, 39 (1A), $163-170$.

[23] Galindo-Gonzalez, C.; Feinberg, J. M.; Kasama, T.; Gontard, L. C.; Pósfai, M.; Kósa, I.; Duran, J. D.; Gil, J. E.; Harrison, R. J.; Dunin-Borkowski, R. E. Magnetic and Microscopic Characterization of Magnetite Nanoparticles Adhered to Clay Surfaces. American Mineralogist 2009, 94 (8-9), 1120-1129.

[24] Bunnak, N.; Ummartyotin, S.; Laoratanakul, P.; Bhalla, A. S.; Manuspiya, H. Synthesis and Characterization of Magnetic Porous Clay Heterostructure. Journal of Porous Materials 2014, 21 (1), 1-8.

[25] Liu, H.; Chen, W.; Liu, C.; Liu, Y.; Dong, C. Magnetic Mesoporous Clay Adsorbent: Preparation, Characterization and Adsorption Capacity for Atrazine. Microporous and Mesoporous Materials 2014, $194,72-78$.

[26] Marins, J. A.; Mija, A.; Pin, J.-M.; Giulieri, F.; Soares, B. G.; Sbirrazzuoli, N.; Lançon, P.; Bossis, G. Anisotropic Reinforcement of Epoxy-Based Nanocomposites with Aligned Magnetite-Sepiolite Hybrid Nanofiller. Composites Science and Technology 2015, 112, 34-41.

[27] Barry, M. M.; Jung, Y.; Lee, J.-K.; Phuoc, T. X.; Chyu, M. K. Fluid Filtration and Rheological Properties of Nanoparticle Additive and Intercalated Clay Hybrid Bentonite Drilling Fluids. Journal of Petroleum Science and Engineering 2015, 127, 338-346.

[28] Middea, A.; Spinelli, L. S.; Junior, F. G. S.; Neumann, R.; da FM Gomes, O.; Fernandes, T. L.; de Lima, L. C.; Barthem, V. M.; de
Carvalho, F. V. Synthesis and Characterization of Magnetic Palygorskite Nanoparticles and Their Application on Methylene Blue Remotion from Water. Applied Surface Science 2015, 346, 232-239.

Bailey, L.; Lekkerkerker, H. N.; Maitland, G. C. Smectite Clay-Inorganic Nanoparticle Mixed Suspensions: Phase Behaviour and Rheology. Soft Matter 2015, 11 (2), 222-236.

[30] Massart, R. Preparation of Aqueous Magnetic Liquids in Alkaline and Acidic Media. IEEE Transactions on Magnetics 1981, 17 (2), 1247-1248. https://doi.org/10.1109/TMAG.1981.1061188.

[31] Paineau, E.; Antonova, K.; Baravian, C.; Bihannic, I.; Davidson, P.; Dozov, I.; Impéror-Clerc, M.; Levitz, P.; Madsen, A.; Meneau, F. Liquid-Crystalline Nematic Phase in Aqueous Suspensions of a Disk-Shaped Natural Beidellite Clay. The Journal of Physical Chemistry B 2009, 113 (48), 15858-15869.

[32] Charlot, G. Les Méthodes de La Chimie Analytique, Quatriême Édition; Masson et Cie, 1961.

[33] Beaucage, G. Approximations Leading to a Unified Exponential/Power-Law Approach to Small-Angle Scattering. J Appl $\begin{array}{lllll}\text { Cryst } & \mathbf{1 9 9 5}, & 28 & \text { (6), }\end{array}$ https://doi.org/10.1107/S0021889895005292.

[34] Bacri, J.-C.; Perzynski, R.; Salin, D.; Cabuil, V.; Massart, R. Magnetic Colloidal Properties of Ionic Ferrofluids. Journal of Magnetism and Magnetic Materials 1986, 62 (1), 36-46.

[35] Lucas, I. T.; Durand-Vidal, S.; Dubois, E.; Chevalet, J.; Turq, P. Surface Charge Density of Maghemite Nanoparticles: Role of Electrostatics in the Proton Exchange. The Journal of Physical Chemistry C 2007, 111 (50), 18568-18576.

[36] Remy, J. C.; Orsini, L. Utilisation du chlorure de cobaltihexammine pour la détermination simultanée de la capacité d'échange et des bases échangeables des sols. Science du Sol 1976 4, 269-275.

[37] Paineau, E.-N. Transitions de phases dans les argiles. Influence de la minéralogie et de la morphologie. Comportement sous écoulement et sous champs. PhD Thesis, Vandoeuvre-les-Nancy, INPL, 2011.

[38] Lagaly, G.; Ziesmer, S. Colloid Chemistry of Clay Minerals: The Coagulation of Montmorillonite Dispersions. Advances in Colloid and Interface $\quad$ Science $\quad$ 2003, 100-102, 105-128. https://doi.org/10.1016/S0001-8686(02)00064-7.

[39] Michot, L. J.; Bihannic, I.; Thomas, F.; Lartiges, B. S.; Waldvogel, Y.; Caillet, C.; Thieme, J.; Funari, S. S.; Levitz, P. Coagulation of Na-Montmorillonite by Inorganic Cations at Neutral pH. A Combined Transmission X-Ray Microscopy, Small Angle and Wide Angle X-Ray Scattering Study. Langmuir 2013, 29 (10), 3500-3510. https://doi.org/10.1021/la400245n.

[40] Michot, L. J.; Bihannic, I.; Porsch, K.; Maddi, S.; Baravian, C.; Mougel, J.; Levitz, P. Phase Diagrams of Wyoming Na-Montmorillonite Clay. Influence of Particle Anisotropy. Langmuir 
2004, 20 (25), 10829-10837. https://doi.org/10.1021/la0489108.

[41] Tadros, T. F. Solid-Liquid Dispersions; Academic Press, 1987.

[42] Wilhelm, C.; Gazeau, F.; Bacri, J.-C. Magnetophoresis and Ferromagnetic Resonance of Magnetically Labeled Cells. European Biophysics Journal 2002, 31 (2), 118-125.

[43] Berret, J.-F.; Sandre, O.; Mauger, A. Size Distribution of Superparamagnetic Particles Determined by Magnetic Sedimentation. Langmuir 2007, 23 (6), 2993-2999.

[44] White, D. A.; Amornraksa, S. Batch Sedimentation of Magnetic Flocs in a Magnetic Field. Chemical Engineering Journal 2000, 79 (2), $165-169$.

[45] Turchiuli, C.; Fargues, C. Influence of Structural Properties of Alum and Ferric Flocs on Sludge Dewaterability. Chemical Engineering Journal 2004, 103 (1-3), 123-131. 

(1.94) UNIVERSITY PRESS 